во «Нурлан», 2001. С. 144.

13. Мусеибли Наджаф. Энеолитическое поселение Беюк Кесик. Баку: Изд-во «Nafta - Press», 2007. C. 225 .

14. Крупнов Е.И. Древняя история и культура Кабарды. М.: Наука, 1957. С. 46-67.

15. Иессен А.А. К хронологии больших кубанских курганов // СА, №XII. М., 1950. С. 157-200.

16. Иессен А.А. Майкопская культура и ее датировка // Тезисы докладов на заседаниях Отделения исторических наук АН СССР, посвященных итогам полевых исследований 1961 г. М., 1962. С.9.

17. Мунчаев Р.М. Кавказ на заре бронзового века. М.: Наука, 1975. С. 414.
18. Мунчаев Р.М. Майкопская культура // Археология эпохи бронзы Кавказа и Средней Азии: Ранняя и средняя бронза Кавказа. М.: Наука. С. 158-225.

19. Мунчаев Р.М., Амиров Ш.Н., Магомедов Р.М. Восточный Кавказ и проблема Кавказско-Месопотамских связей в IV-III тыс. до н.э. // Исследования первобытной археологии Евразии. Махачкала: Изд-во «Наука ДИЦ», 2010. С. 316-334.

20. Van der Leeuw, Sander E. Giving the Potter a Choice: Conceptual aspects of pottery techniques // Pierre Lemonnier (ed.), Technological Choices: Transformation in material cultures since the Neolithic. London, New York, 1993. P.238-288.

\title{
ON THE STUDY OF THE MANUFACTURING TECHNIQUES DEALS WITH THE CERAMICS OF THE MAIKOP-NOVOSVOBODNAYA COMMUNITY BY THE METHOD OF . A. A. BOBRINSKY AND NEW EXPERIMENTS
}

(C) 2015

\author{
S.N. Korenevskiy, Doctor of Historical Sciences \\ The Institute of archaeology of the Russian Academy of Sciences, Moscow (Russia) \\ A.S. Kizilov, candidate of pedagogical Sciences, \\ associate professor of the Department of humanitarian disciplines (specializing in design) \\ International Innovative University, Sochi (Russia)
}

\begin{abstract}
The article presents a brief synthesis of the results deal with the study of ceramics MaikopNovosvobodnaya community using the method of A. A. Bobrinsky and use of the microscope with 12 times magnification. It sets out ideas about raw materials, methods of construction, surface treatment. Especially emphasized the problem of the use by the ancient potters of rotary devices. For the first time about such vessels were noted in the work of A. A. Bobrinsky and R. M. Munchaev in 1966, for example, vessels with a flat bottom. At present a series of examples of traces deal with use of rotary devices has expanded. In the article by A. S. Kizilov shows the simulation of the vessel of the Maikop culture and fixation of the traces of its turn without a fixed axis of rotation and with a non-fixed environment of rotation. As a result, the actual doing of those and other traces that prove the use of Maikop potters rotary devices with a fixed axis of rotation in the manufacture of vessels not only flat, but round bottom toо.круговая керамика; лепная керамика.
\end{abstract}

Keywords: ceramics; Maikop-Novosvobodnaya community; microscope; mineral impurities; organic impurities; signs; experiment; rotary device; pottery; wheel - made pottery; hand made pottery; potter's wheel.

УДК 903.02

(C) 2015

\section{ПРИВОЗНАЯ КЕРАМИКА НА ПОСЕЛЕНИИ КЕНТ}

\author{
В.Г. Ломан, кандидат исторических наук, \\ директор Сарыаркинского археологического института \\ Карагандинский государственный университет имени академика Е.А. Букетова, \\ Караганда (Казахстан)
}

\footnotetext{
Аннотация. В финале эпохи бронзы территория степного пояса Евразии была занята общностью культур валиковой керамики. Несмотря на огромные расстояния, разделяющие памятники, керамические сосуды этих культур обладают большой степенью внешнего сходства. Глубину культурных различий групп древнего населения позволяет, в частности, определить технико-технологический анализ керамики. К сожалению, такой анализ для большинства культур ОКВК не проводился, что в значительной степени затрудняет работу по установлению степени их родственности и выявлению существовавших между ними контактов. Статья посвящена анализу керамического комплекса поселения Кент - крупнейшего для саргаринско-алексеевской культуры, входившей в ОКВК. Было обнаружено, что население, оставившее памятник, состояло из не менее 3-4-х групп, между которыми проходили процессы смешения. Из всего керамического комплекса на основе сравнения результатов технико-технологического анализа выявлена керамика, привезенная из родственных общин. Кроме этого, рассмотрена гончарная технология образцов инокультурной посуды, и сделаны выводы об исходных территориях ее происхождения. К инокультурным отнесены сосуды, орнамент и форма которых находят аналогии в синхронных археологических культурах Западной Сибири и Средней 
Азии. Установлено, что керамика, поступавшая из Средней Азии, была сконструирована способами скульптурной лепки, а гончарный круг применялся лишь для профилирования основной части емкости. Сделан вывод о том, что саргаринско-алексеевские коллективы не представляли собой замкнутые сообщества. Они находились в постоянных контактах с однокультурными поселениями и торгово-обменных отношениях с населением соседних территорий.

Ключевые слова: эпоха бронзы; саргаринско-алексеевская культура; дандыбаевская посуда; круговая керамика; гончарная технология; технико-технологический анализ

Керамика саргаринско-алексевской культуры, занимавшей в финале эпохи бронзы территорию Зауралья, Казахстана и Алтая, повсюду выглядит достаточно однообразной по форме и орнаменту, среди элементов которого присутствуют «елочка», зигзаги, «сетка», горизонтальные линии, встречаются различные треугольники. Располагается орнамент в основном по плечику сосудов [1, с. 87], некоторые элементы, например, пальцевые защипы, могут покрывать все тулово. В керамический комплекс входят горшки, украшенные по шейке налепными валиками с X-образными насечками или наклонными отпечатками гладкого штампа, что в целом, несомненно, имитирует веревку, обвязывающую устье емкости. Подобные горшки являются неотъемлемой частью материальной культуры синхронных памятников степного пояса Евразии, по которому их совокупность получила название общности культур валиковой керамики (ОКВК [2]). Материальная культура ОКВК весьма схожа во всех регионах ее распространения. Например, многие сосуды неотличимы по внешнему виду, несмотря на огромные расстояния, разделяющие памятники.

Как известно, технико-технологический анализ керамики позволяет, в частности, определить глубину культурных различий тех групп древнего населения, к которым принадлежали гончары [3, с. 244]. К сожалению, такой анализ для большинства культур ОКВК не проводился, что в значительной степени затрудняет работу по установлению степени их родственности и выявлению существовавших между ними контактов.

В настоящее время наиболее исследованной в этом смысле является керамика саргаринско-алексеевской культуры. В общей сложности автором этой статьи было изучено более 1100 образцов из 15 памятников Казахстана и Алтая (часть результатов исследований опубликована $[4 ; 5 ; 6 ; 7])$. На примере всех поселений очевиден сложный, многокомпонентный состав их населения. Особенно это проявляется по материалам крупнейшего саргаринско-алексеевского поселения Кент (Казахстан, в 210 км к юго-востоку от г. Караганды).

По результатам микроскопического анализа, проведенного по методике А.А. Бобринского [3; 8], обнаружено, что гончары поселения в качестве исходного сырья пользовались в основном $(83,4 \%$ изученных образцов) среднеожелезненными глинами, а в качестве искусственных минеральных добавок применяли главным образом кварцитовую дресву (68,7\% образцов) и шамот (в среднем по памятнику более 17\% образцов). Дресва предпочиталась крупной размерности (60,2\%), преобладающей концентрацией было соотношение 1:5 (в среднем по памятнику 50,3\% образцов с дресвой). В рецепт формовочной массы входил также навоз жвачных животных в небольшой концентрации, скорее всего в виде органического раствора.

По фрагментам придонных частей и археологически целым сосудам был выявлен ряд технологических схем, по которым изготавливалась керамика:

1 - донно-емкостный лоскутно-комковатый начин с лоскутно-комковатым полым телом $(44,4 \%)$, варианты: а) из одного слоя лоскутов $(75,6 \%)$ и б) из двух слоев лоскутов $(24,4 \%)$;

2 - донно-емкостный лоскутно-спиральный начин с лоскутно-спиральным полым телом (4\%);

3 - емкостный начин с лоскутно-комковатым полым телом (22\%);

4 - донно-емкостный спирально-жгутовой начин со спирально-жгутовым полым телом (21,3\%), варианты: а) из одного слоя жгутов $(79,7 \%)$ и б) из двух слоев жгутов $(20,3 \%)$;

5 - донный начин со спирально-жгутовым полым телом $(8,3 \%)$.

По наиболее представленным технологическим схемам можно судить, что на поселении Кент было не менее трех-четырех групп производителей керамики с разными гончарными традициями.

Между этими группами гончаров проходили процессы смешения, которые нашли свое отражение в смешанных рецептах формовочных масс («шамот+дресва» - в среднем по памятнику $12,1 \%$ образцов) и приемах конструирования. Так, 30,9\% сосудов первой технологической схемы изготавливались в формах-емкостях с округлым дном, и поэтому сами имели первоначально округлое дно, которое затем уплощалось путем примазывания снаружи глиняного диска. В подражание этому приему у 25,4\% сосудов четвертой технологической схемы днища были оформлены таким же образом. Часть кентских гончаров, изготавливавших керамику с донно-емкостными спирально-жгутовыми начинами, стала, под влиянием двухслойного лоскутно-комковатого способа, делать сосуды с полым телом из двух слоев жгутов (технологическая схема №4 «б»). С другой стороны, незначительное количество сосудов с лоскутно-спиральным полым телом (технологическая схема №2) можно рассматривать в данном контексте как результат обратного воздействия спирально-жгутового способа на лоскутно-комковатый.

Простой статистический подсчет показывает, что основной группой населения памятника была та, гончары которой при конструировании сосудов применяли первую технологическую схему и составляли формовочную массу по рецепту «среднеожелезненная 
глина + крупная кварцитовая дресва в концентрации $1: 5+$ навоз в небольшой концентрации». Данная группа доминировала в процессах культурного смешения, проходивших на поселении.

Наряду с этим оказалось возможным выявить привозную керамику, которая состоит из двух категорий: 1) керамика, доставленная из родственных общин и 2) принадлежавшая иным культурам.

К первой следует отнести фрагменты немногочисленных сосудов, имеющих саргаринско-алексеевский внешний облик, но отличающихся от основной массы керамики поселения по особенностям рецептуры формовочной массы и конструирования. Например, такие, полое тело которых изготовлено из лент (рис. 1: 1-3); с большой (1:2) концентрацией дресвы (рис. 1: 4-6); с большой концентрацией навоза (рис. 1: 7, 8, 10, 12); с добавкой песка (рис. 1: 9, 11). В эту же категорию, ввиду малой представленности образцов, может входить керамика пятой технологической схемы (с донными спирально-жгутовыми начинами).

Вторая категория привозной керамики была визуально выделена основным исследователем поселения Кент В.В. Варфоломеевым [9, с. 15] и впоследствии названа им суперстратной [10, с. 59; 11]. Сюда включены сосуды, орнамент и форма которых находят аналогии в синхронных археологических культурах Западной Сибири (рис. 2) и Средней Азии.

Не подлежит сомнению среднеазиатское происхождение находок керамики, изготовленной с помощью гончарного круга (рис. 3). Она обнаруживает сходство с посудой некоторых среднеазиатских культур конца эпохи бронзы, например, поздней фазы Намазга-VI Таджикистана и саппалитепа Южного Узбекистана [11, с. 175-177]. Добавим, что на алтайском саргаринско-алексеевском поселении Бурла-3 совместно с подобной круговой керамикой были найдены биконическое пряслице и целая серия конусовидных керамических подставок - вещи, также характерные для культуры Намазга-6 [12, с. 109].

Всего на поселении Кент насчитано около 250 фрагментов от круговых сосудов. Из них были выделены фрагменты с венчиками от 11 сосудов, стенок от 26 сосудов и придонная часть с днищем от одного сосуда.

Очевидно, что круговая посуда составляет в керамическом комплексе поселения весьма незначительный процент. При этом по различиям в естественных примесях и степени ожелезненности в ней выделено 9 видов исходного сырья, что говорит о ее происхождении от разных производителей с разными навыками отбора глины и, возможно, о том, что она могла быть привезена в разное время:

1) неожелезненная глина с примесью очень мелкого (до 0,5 мм) полупрозрачного кварцевого песка в концентрации 1:2 - 17,9\%;

2) неожелезненная глина с примесью мелкого полупрозрачного кварцевого песка в концентрации $1: 1-2,6 \%$ (1 экз.);

3) слабоожелезненная глина с мелким полупрозрачным кварцевым песком в концентрации 1:2 и очень мелким оолитовым бурым железняком - 33,3\%;

4) слабоожелезненная глина с мелким белым песком в концентрации 1:3 и мелким оолитовым бурым железняком - 7,7\%;

5) слабоожелезненная высокопластичная глина с примесью очень мелкого оолитового бурого железняка - 2,6\%;

6) среднеожелезненная высокопластичная глина без заметных естественных примесей - 7,7\%;

7) среднеожелезненная глина с мелким разноцветным песком в концентрации 1:4 и мелким оолитовым бурым железняком - 2,6\%;

8) среднеожелезненная глина с мелким полупрозрачным кварцевым песком в концентрации 1:5 $-10,3 \%$;

9) смесь из двух глин: сухой неожелезненной и влажной слабоожелезненной с примесью мелкого полупрозрачного кварцевого песка в концентрации $1: 2$ и мелкого оолитового бурого железняка - 15,3\%.

В формовочной массе преобладающей части сосудов не зафиксировано каких-либо искусственных добавок, лишь в $9(23,7 \%)$ экземплярах из 38 отмечено незначительное присутствие органического раствора, на что указывает наличие в изломе мелких аморфных и удлиненных пустот с белесым налетом на стенках. По данному рецепту были изготовлены все сосуды, исходное сырье которых принадлежало к видам №№ 5, 6, 8, а также 1 экземпляр с исходным сырьем вида №9.

Зафиксированы следующие способы обработки поверхности: простые - ручное (без помощи гончарного круга) лощение по подсушенной основе $(10,5 \%)$; глиняная обмазка (3 сосуда - 7,9\%), в том числе внутренней поверхности у 2-х сосудов, внешней - у 1-го; покрытие ангобом $(26,3 \%)$, в том числе красного цвета - 70\%, кремового - 30\%; смешанные - ручное лощение по подсушенной основе + чернение $(13,2 \%)$; красное ангобирование + ручное лощение по подсушенной основе $(5,3 \%)$; на внутренней поверхности обмазка, на внешней - обтачивание + красное ангобирование (1 экз. - 2,6\%); обтачивание внешней поверхности + красное ангобирование - 10,5\%; обмазка внешней поверхности + красное ангобирование (1 экз. - 2,6\%). У 21,1\% сосудов способы обработки поверхности определить не удалось.

Обжиг 26,3\% экземпляров проводился в восстановительной среде, остальные 73,7\% обжигались в окислительной атмосфере при температуре не менее $850 \mathrm{C}^{\circ}$, поскольку цвет изломов фрагментов не изменился после их выдержки при данной температуре в муфельной печи.

Микроскопический анализ изломов и поверхностей фрагментов установил, что в действительности полое тело всех сосудов было сконструировано способами скульптурной лепки, а в качестве строительных элементов использовались глиняные ленты. Единственная имеющаяся придонная часть имеет признаки емкостного начина с вмазанным изнутри лоскутным донцем. 

основной части емкости, что соответствует четвертому этапу развития его функций (РФК-4 [3, с. 27]) и свидетельствует о ремесленном характере производства [3, с. 29, 34].

Круговая керамика на саргаринско-алексеевских памятниках почти всегда встречается вместе с посудой весьма характерного облика, которую я называю дандыбаевской по имени первого памятника, где она была найдена - могильника Дандыбай [13]. Это явление отмечено не только на казахстанских поселениях - Кент, Домалактас, Байшура [11, с. 175], Буйен [14, с. 114, табл. 40: 13], Павловка [15, рис. 7], Мыржык [16, с. 213], но и на могильниках - Полугора $[17$, с. 77 , рис. 4: 17], Караоба [18, с. 179, рис. 3 : $10,11]$, Тасырбай $[11$, с. 175], а также на алтайских саргаринско-алексеевских поселениях Гусиная Ляга1 [19, с. 158], Рублево-6 [20, с. 131-132], Бурла-3, Кайгородка-3 [12, с. 108; 21, с. 11-12], Песьянов Мыс [22, с. 15] и других. Многими исследователями эта посуда называется бегазы-дандыбаевской или просто бегазинской. Не вдаваясь здесь в подробности, отсылаю читателя к соответствующей статье, где мною были описаны ее основные признаки и предложено обоснование названия [23].

Находки этой керамики достаточно редки - за 80 лет со времени их первого обнаружения можно насчитать лишь до 100 сосудов, причем в это число входят и немногочисленные фрагменты, находимые на поселениях. Целые и реконструируемые сосуды встречаются главным образом в могильниках, а в особо сложных и монументальных погребальных конструкциях они составляют основную часть инвентаря, что дало В.В. Варфоломееву основание считать их принадлежностью субкультуры элитной части общества [11, с. 191-192].

Сосуды, соответствующие внешним критериям дандыбаевской керамики, представлены на Кенте единичными и небольшими по площади фрагментами, из которых только 3 экземпляра удалось подвергнуть технико-технологическому исследованию.

По всем определена одна и та же рецептура формовочной массы (мелкая гранитная дресва в концентрации 1:4 + органический раствор), один и тот же способ конструирования полого тела (лоскутнокомковатый из двух слоев лоскутов). Исходное сырье: высокопластичные среднеожелезненная и слабоожелезненная глины (рис. 4: 1, 2), а также смесь влажной слабоожелезненной глины со среднеожелезненной сухой глиной (рис. 4: 3). Во всех образцах отмечены естественные примеси мелкой слюды и мелкого оолитового бурого железняка. При формообразовании применялось выбивание, поверхности обработаны лощением по подсушенной поверхности, в одном случае - поверх красного ангоба.

Технология изготовления дандыбаевских сосудов почти совсем не изучена. Помимо кентских образцов автору удалось исследовать часть дандыбаевской керамики могильника Караоба из раскопок В.К. Мерца

2001 г. [17, рис. 4]. Оказалось, что вся она была изготовлена по той же технологической схеме: глина (в основном слабоожелезненная) с естественной примесью слюды и мелкого оолитового бурого железняка + мелкая дресва из разных пород камня в концентрации $1: 4+$ органический раствор и лоскутно-комковатое полое тело из двух слоев лоскутов; поверхности подвергались лощению по подсушенной основе. Совпадение гончарных традиций говорит о происхождении дандыбаевской посуды из одного источника, несмотря на значительное расстояние, разделяющее памятники.

В свете рассмотрения вопроса о происхождении дандыбаевской керамики представляется крайне важным еще раз отметить, что один из привозных сосудов поселения Кент (рис. 4: 7) находит полную аналогию (рис. 4: 8) в керамическом комплексе некрополя Северный Тагискен [24, рис. 101: 695], находящегося на берегу р. Жанадарья, в 1083 км к юго-западу от Кента. На этот факт обращали внимание как В.В. Варфоломеев, так и автор этой статьи, выявивший еще ряд таких аналогий по другим памятникам Казахстана [5, с. $237 ; 23$, рис. 6]. В.В. Варфоломеев сравнивает [11, c. 177] оба сосуда с глиняной бутылью из могильника Сумбар-I в Юго-Западной Туркмении [25, табл. IX: 14], которая, в свою очередь, является импортом из Ирана [25, с. 40, рис. 10]. Таким образом, кентская бутыль имеет южное происхождение. Между тем совместно с нею, в той же постройке, были найдены фрагменты горшка (рис. 4: 9), отнесенного В.В. Варфоломеевым по внешним признакам к еловской культуре Западной Сибири [10, с. 57], в памятниках которой, действительно, встречается очень схожая посуда (рис. 4: 10, 11) [26, рис. 385: 6; рис. 392: 8].

Однако технико-технологический анализ показал тождество обоих экземпляров, которые могли быть изготовлены одним мастером (исходное сырье - слабоожелезненная глина с естественными примесями мелкой слюды и мелкого оолитового бурого железняка; рецепт формовочной массы - мелкая гранитная дресва в концентрации 1:3 + органический раствор; полое тело - лоскутно-комковатое из одного слоя лоскутов; обработка поверхности - лощение; формообразование - с использованием выбивания. Результаты технико-технологического анализа показали, что скорее всего тому же мастеру принадлежали еще один сосуд из того же жилища, покрытый лощением поверх красного ангоба и украшенный сосцевидными налепами (рис. 4: 4), и два сосуда из соседней постройки (рис. 4: 5, 6).

Технология изготовления данных сосудов представляется весьма схожей с той, что наблюдалась по «классическим» дандыбаевским: там и там использовались глины с естественными примесями мелкой слюды и мелкого оолитового бурого железняка, мелкая гранитная дресва и незначительная добавка органики, применялись лощение, ангоб и выбивание. Вся разница в концентрации дресвы (1:3 и 1:4) и конструировании полого тела (лоскутнокомковатое в один слой и лоскутно-комковатое в два слоя). Такие незначительные различия не исключают 

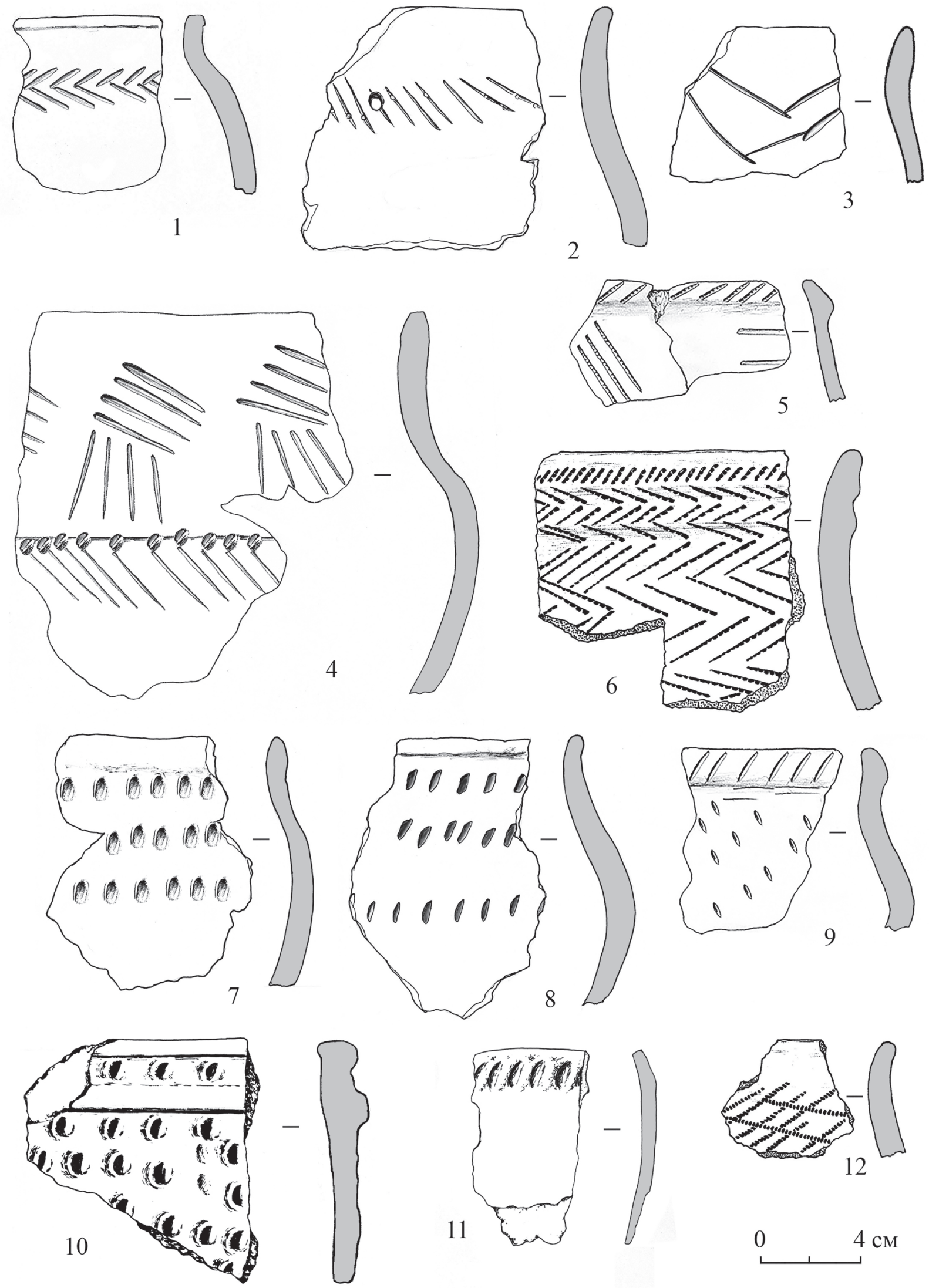

Рисунок 1 - Поселение Кент. Привозная саргаринско-алексеевская керамика 

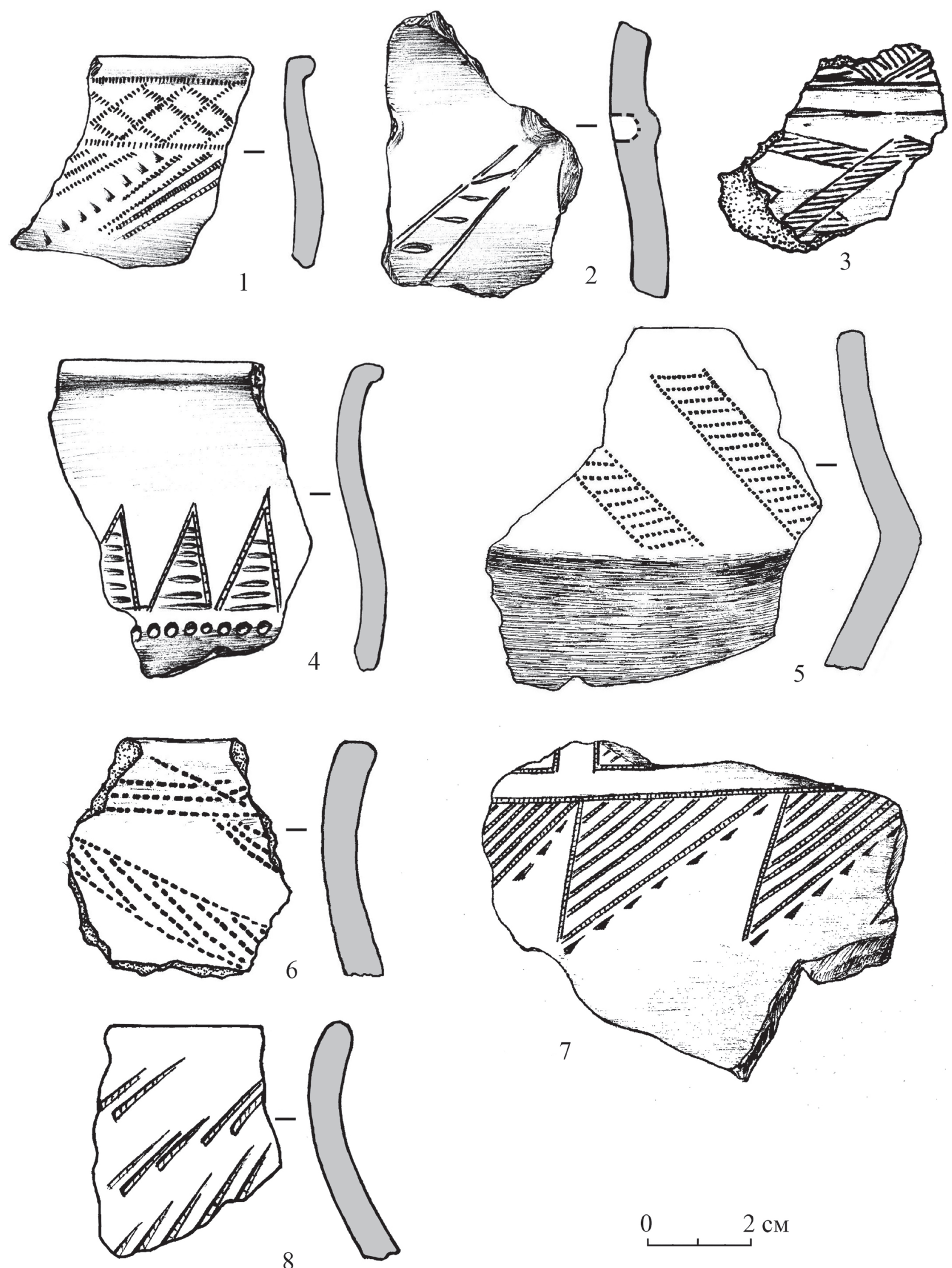

Рисунок 2 - Поселение Кент. Привозная керамика из Западной Сибири (по В.В. Вафоломееву [11]) 

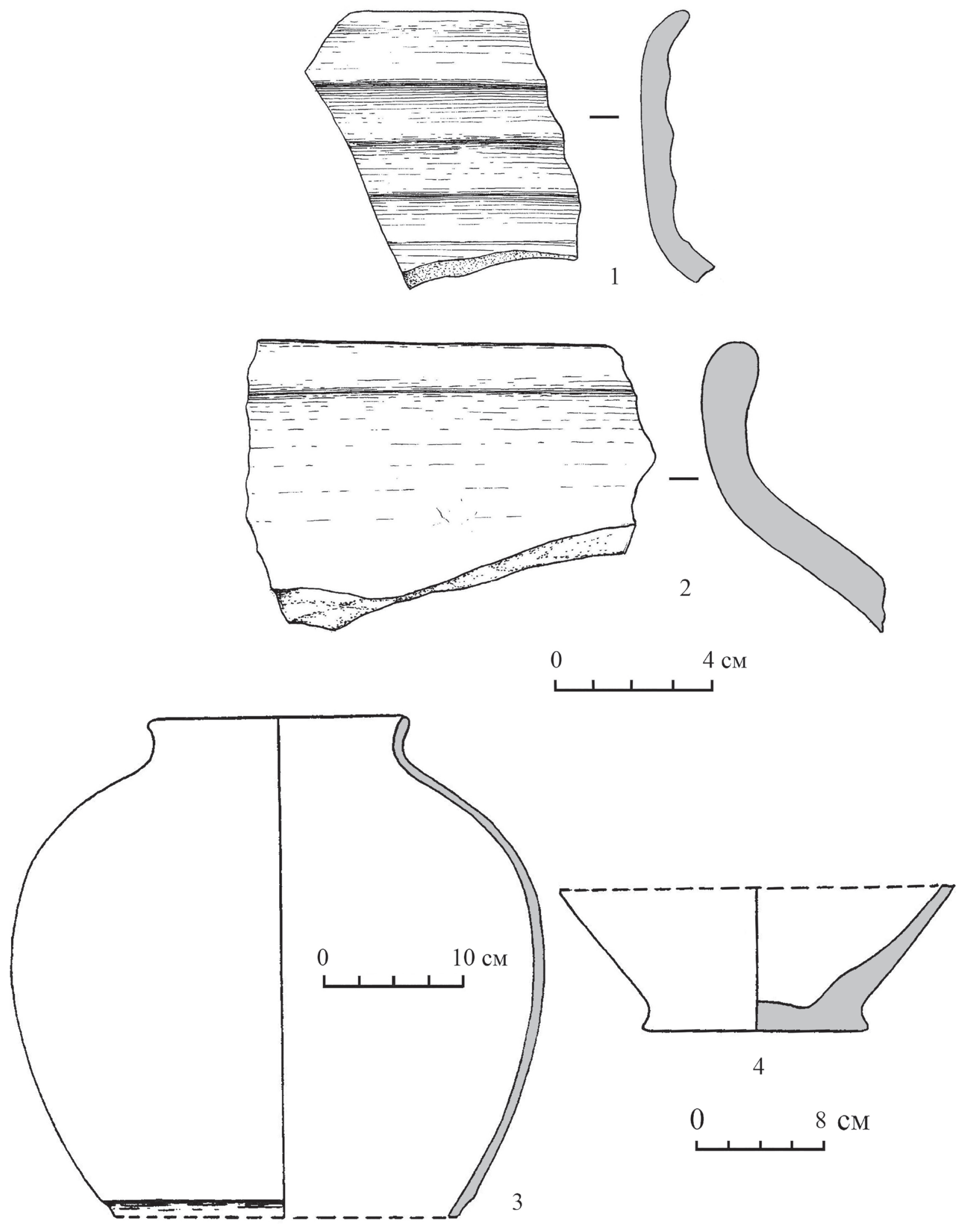

Рисунок 3 - Поселение Кент. Привозная круговая керамика 
В.Г. Ломан

ПРИRО2Н А Я КЕРА МИКА НА ПОСЕ ПFНИИ КЕНТ

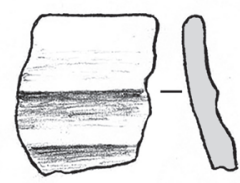

1

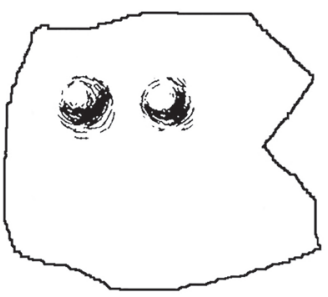

4

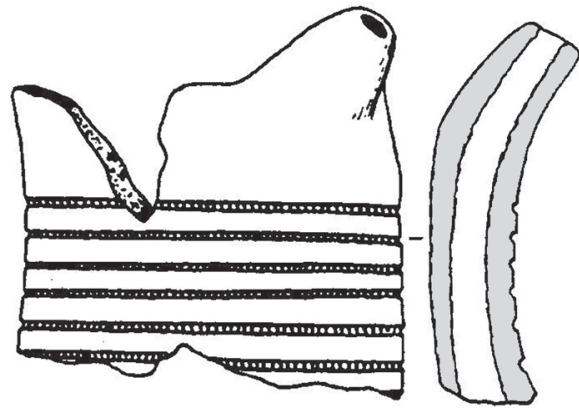

7
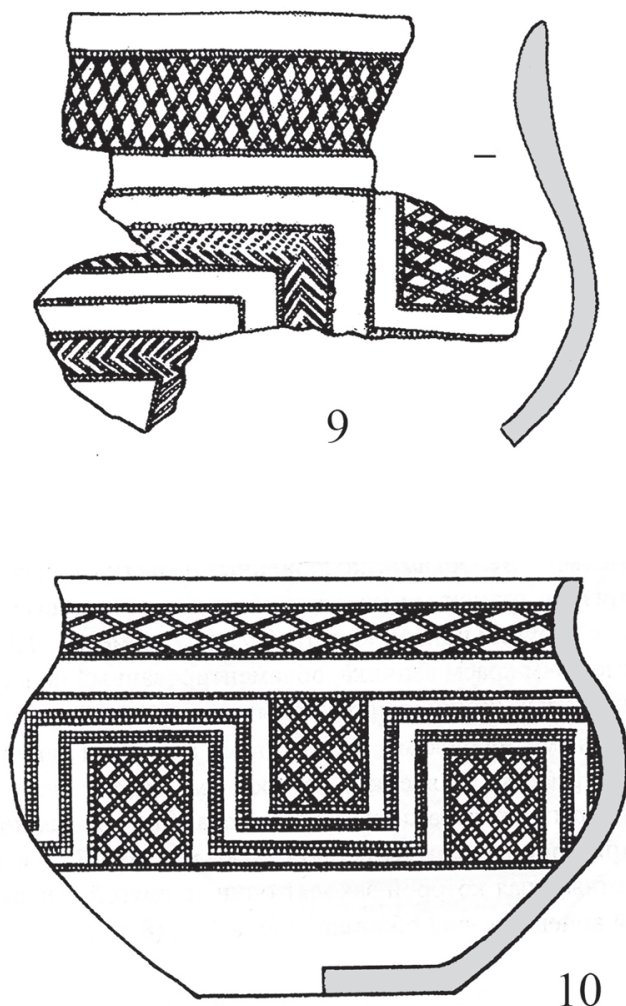

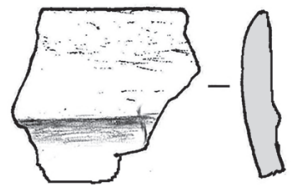

2

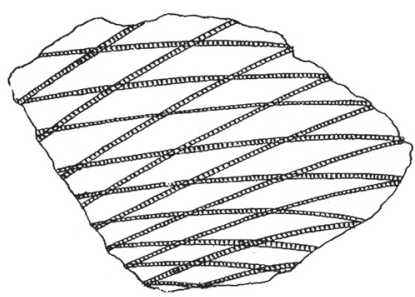

5

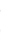

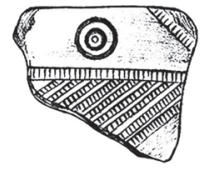

3

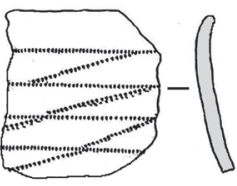

6

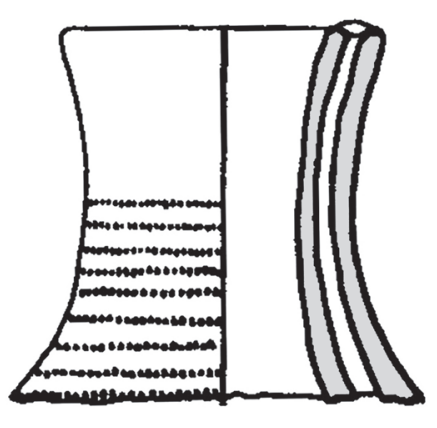

8

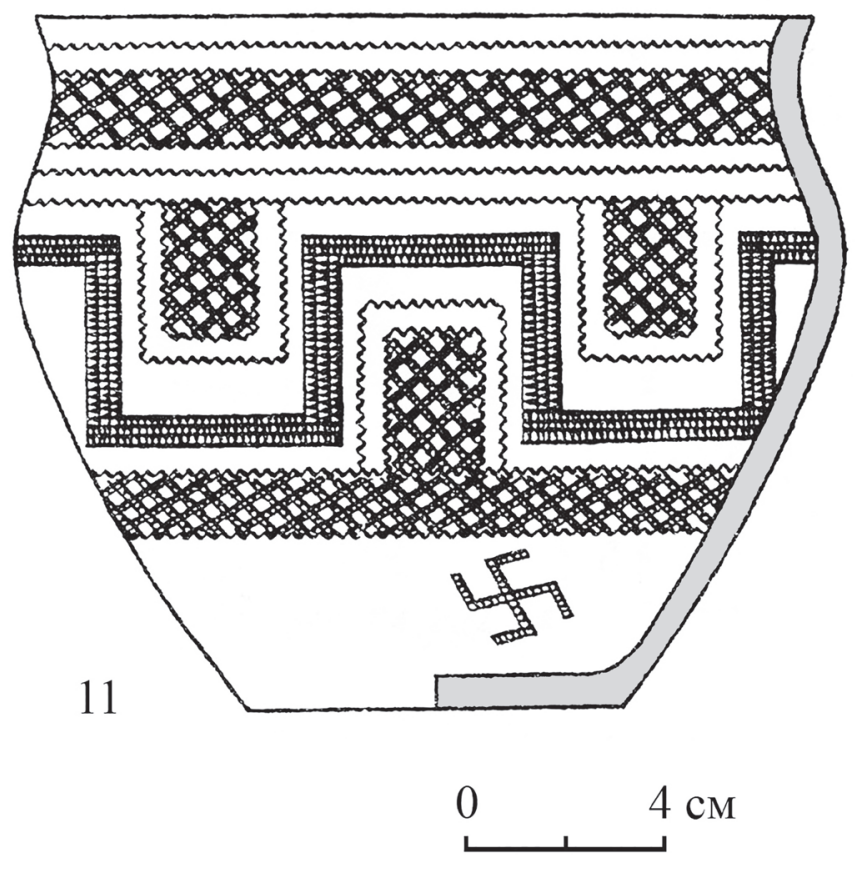

Рисунок 4 - Поселение Кент. Керамика дандыбаевского типа и ее аналоги 
принадлежности всех вышеописанных сосудов к одной этнокультурной группе, и, опираясь на данные технико-технологического анализа, следует, видимо, расширить номенклатуру форм и орнамента дандыбаевской керамики в дополнение к той, что была описана ранее [23].

В число аргументов в пользу южного происхождения дандыбаевских сосудов, помимо вышеописанных аналогий, следует включить частоту их совместного нахождения со среднеазиатской круговой посудой, а также тот факт, что поверхность некоторых из них покрывалась ангобом и затем лощилась так же, как это отмечено на ряде экземпляров круговой керамики. Как известно, ангобирование керамики характерно для среднеазиатских культур, начиная с энеолита.

Итак, наличие разнообразной привозной посуды говорит о том, что саргаринско-алексеевские коллективы не представляли собой замкнутые сообщества. Они находились в постоянных контактах с однокультурными поселениями и торгово-обменных отношениях с населением соседних территорий. Западносибирская керамика попадала в Казахстан через посредство алтайских саргаринско-алексеевских общин, а с юга поступала дандыбаевская и круговая посуда. Дандыбаевская входила в престижную часть бытового и погребального инвентаря, круговая, представленная преимущественно большими формами, выполняла роль тары при перевозке сыпучих и жидких продуктов.

В заключение, немного отвлекшись от темы статьи, следует сказать, что в будущем, очевидно, предстоит скорректировать решение проблемы формирования керамического комплекса еловской культуры, поскольку некоторые сосуды, считавшиеся типичными для нее, происходят, как оказалось, из значительно более южных территорий.

\section{СПИСОК ЛИТЕРАТУРЫ:}

1. Зданович С.Я. Керамика саргаринской культуры // Бронзовый век Урало-Иртышского междуречья. Челябинск: Изд-во БашГУ, 1984. С. 79-96.

2. Черных Е.Н. Проблема общности культур валиковой керамики в степях Евразии // Бронзовый век степной полосы Урало-Иртышского междуречья. Челябинск: Изд-во БашГУ, 1983. С. 81-99.

3. Бобринский А.А. Гончарство Восточной Европы. Источники и методы изучения. М.: Наука, 1978. 272 с.

4. Ломан В.Г. Особенности гончарной технологии эпохи поздней бронзы Центрального Казахстана // КСИА. 1991. Вып. 203. С. 47-53.

5. Бейсенов А.3., Ломан В.Г. Древние поселения Центрального Казахстана. Алматы, 2009. 264 с.

6. Бейсенов А.3., Ломан В.Г. Керамика поселения эпохи поздней бронзы Кекиликты-1 (Северо-Восточный Жетысу) // Вопросы археологии Казахстана. 2011. Вып. 3. С. 244-255.

7. Бейсенов А.З., Ломан В.Г., Касеналин А.Е. Новое в археологии Сарыарки: донгальские погребения могильника Кызыл // Бегазы-дандыбаевская культура степной Евразии. Алматы, 2013. С. 59-73.
8. Бобринский А.А. Гончарная технология как объект историко-культурного изучения // Актуальные проблемы изучения древнего гончарства. Самара: Издво СамГПУ, 1999. С. 5-109.

9. Варфоломеев В.В. Сарыарка в конце бронзовой эпохи: Автореф. дисс. ...канд. ист. наук. Алма-Ата, 1991. $21 \mathrm{c.}$

10. Евдокимов В.В., Варфоломеев В.В. Эпоха бронзы Центрального и Северного Казахстана. Караганда: Изд-во КарГУ, 2002. 138 с.

11. Варфоломеев В.В. Керамика суперстратного облика из памятников бегазы-дандыбаевской культуры // Бегазы-дандыбаевская культура степной Евразии. Алматы, 2013. С. 167-197.

12. Удодов В.С. Эпоха поздней бронзы Кулунды (к постановке вопроса) // Хронология и культурная принадлежность памятников каменного и бронзового веков Южной Сибири. Барнаул: Изд-во ИИФиФ; АГУ, 1988. С. 107-110.

13. Грязнов М.П. Памятники карасукского этапа в Центральном Казахстане // СА. 1952. №XVI. С. 129162.

14. Карабаспакова К.М. Жетысу и Южный Казахстан в эпоху бронзы. Алматы, 2011. 220 с.

15. Малютина Т.С. Стратиграфическая позиция материалов федоровской культуры на многослойных поселениях казахстанских степей // Древности Восточно-Европейской степи. Самара: Изд-во СамГПУ, 1991. С. 141-162.

16. Кадырбаев М.К., Курманкулов Ж. Культура древних скотоводов и металлургов Сары-Арки. Алматы, 1992. 247 с.

17. Мерц В.К. Археологические исследования в Бескарагае // Алтай в системе металлургических провинций бронзового века. Барнаул: Изд-во Алт. ун-та, 2006. С. 73-82.

18. Бейсенов А.З., Варфоломеев В.В., Мерц В.К., Мерц И.В. Раскопки могильника Караоба в 2013 г. (предварительное сообщение) // Диалог культур Евразии в археологии Казахстана. Астана: Сарыарка, 2014. С. 173-186.

19. Ситников С.М., Гельмель Ю.И. Новые материалы финальной бронзы Северной Кулунды // Сохранение и изучение культурного наследия Алтая. Вып. ХІ. Барнаул: Изд-во Алт. Ун-та, 2000. С. 158-161.

20. Папин Д.В., Федорук А.С. Хозяйственно-культурный центр эпохи поздней бронзы Рублево-VI // Археологические исследования Степной Евразии. Караганда: Tengri Ltd, 2013. С. 129-149.

21. Удодов В.С. Эпоха развитой и поздней бронзы Кулунды: Автореф. дисс. ...канд. ист. наук. Барнаул, 1994. $21 \mathrm{c.}$

22. Папин Д.В., Федорук А.С., Фролов Я.В., Редников А.А. Поселение эпохи поздней бронзы Песьянов Мыс // Древности Сибири и Центральной Азии. Горно-Алтайск: Изд-во ГАГУ, 2013. №5 (17). С. 14-22.

23. Ломан В.Г. О культурных типах памятников финала эпохи бронзы Казахстана // Бегазы-дандыбаевская культура степной Евразии. Алматы, 2013. C. 247-259. 

ного Тагискена. Поздний бронзовый век Нижней Сырдарьи. М.: Восточная литература РАН, 2001. 295 с.

25. Хлопин И.Н. Юго-Западная Туркмения в эпоху поздней бронзы. По материалам Сумбарских могиль-

ников. Л.: Наука, 1983. 242 с.

26. Матющенко В.И. Еловский археологический комплекс. Часть вторая. Еловский II могильник. Доирменские комплексы. Омск: Изд-во ОмГУ, 2004. 468 с.

(C) 2015

\section{IMPORTED CERAMICS FROM THE SETTLEMENT KENT}

V.G. Loman, candidate of history sciences, director of the Saryarka Archaeological Institute E.A. Buketov Karaganda State University, Karaganda (Kazakhstan)

Abstract. At the end of the Bronze Age so-called community of the roll ceramics cultures (CRCC) occupied the territory of the steppe belt of Eurasia. Despite the vast distances that separate sites, ceramic vessels of these cultures have a high degree of resemblance. The technical and technological analysis of pottery enables, in particular, to determine the depth of the cultural differences of the ancient population groups. Unfortunately, such analysis for most cultures of the CRCC not carried out, and this fact greatly complicates the work to establish the degree of kinship and identification of contacts existed between them. This article analyzes the ceramic assemblage of Kent settlement - the largest for Sargary-Alekseev culture, part of CRCC. It was found that the population that left the site, consisted of not less than 3-4 groups, which were in the process of mixing. On the base of comparison of the results of technical and technological analysis it was found the pottery, imported from related communities. In addition, the technology of foreign culture pottery samples is considered and conclusions about areas of their origin are made. Vessels with ornaments and shape similar to the synchronous archaeological cultures of Western Siberia and Central Asia are attributed as foreign. It was found that ceramics, coming from Central Asia, was constructed by sculptural modeling methods, and a potter's wheel was used only for profiling the main part of the container. It is concluded that Sargary-Alekseev groups were not closed communities. They were in constant contact with related settlements and also in trade and exchange relations with the population of neighboring areas.

Keywords: the Bronze Age; Sargary-Alekseev culture; Dandybay pottery; wheel-made ceramics; pottery technology; technical and technological analysis

УДК 902.2

\section{ТЕХНИКО-ТЕХНОЛОГИЧЕСКИЙ АНАЛИЗ КЕРАМИКИ ИЗ МОГИЛЬНИКА СТАРО-ЯППАРОВО-1}

(C) 2015

В.И. Мухаметдинов, инженер учебно-научной археологической лаборатории Башкирский государственный университет, Уфа (Россия)

$\boldsymbol{A} . \boldsymbol{K}$ Б Бахшиева, хранитель фондов учебно-научного археологического музея Башкирский государственный университет, Уфа (Россия)

Аннотация. Статья посвящена проблеме срубно-алакульских контактов. В ней представлены результаты технико-технологического анализа керамики из курганного могильника Старо-Яппарово-1, расположенного в Республике Башкортостан. Были получены данные об отборе и обработке исходного сырья, составлении рецептов формовочных масс, способе конструирования начинов и полых тел, орнаментации и термической обработке. Было отмечено, что способы изготовления сосудов, зафиксированные по керамике со СтароЯппаровского могильника, были массово распространены на развитом этапе существования срубной КИО. Эти данные могут скорректировать первоначальные представления о хронологической позиции памятника, полученные по результатам исследования погребального обряда. Анализ позволил выделить как срубные, так и алакульские гончарные традиции, что свидетельствует о культурных контактах. Был сделан вывод, что население, оставившее курганный могильник Старо-Яппарово-1 было неоднородным, но относящееся при этом, в основном, к срубной историко-культурной общности.

Отсутствие в формовочных массах сосудов с памятника тальковой дресвы - надежного индикатора алакульского гончарства в Зауралье, а также отсутствие ее в составе шамота, позволяет сказать, что влияние алакульских племен на данной территории было не прямым, а опосредованным, через контактную зону в степном Приуралье.

Ключевые слова: Южный Урал; поздняя бронза; гончарные традиции; культурные контакты; алакульская культурно-историческая общность; срубная культурно-историческая общность.

Одной из наиболее актуальных проблем в изучении позднего бронзового века Южного Урала остается проблема срубно-алакульских контактов. Особенно пристальное внимание при ее разработке оказывается вопросам времени начала межкультурного взаимодействия, направления движения культурных групп 